\title{
Experimental Study on Bond Behavior between Plain Reinforcing Bars and Concrete
}

\author{
Guohua Xing, Cheng Zhou, Tao Wu, and Boquan Liu \\ School of Civil Engineering, Chang'an University, Xian 710061, China \\ Correspondence should be addressed to Guohua Xing; guohuachd@yahoo.com
}

Received 30 April 2015; Revised 14 August 2015; Accepted 16 August 2015

Academic Editor: Robert Cerný

Copyright ( 2015 Guohua Xing et al. This is an open access article distributed under the Creative Commons Attribution License, which permits unrestricted use, distribution, and reproduction in any medium, provided the original work is properly cited.

\begin{abstract}
To evaluate the bond behavior between the reinforcing bar and surrounding concrete, a total of six-group pullout specimens with plain steel bars and two-group specimens with deformed steel bars, serving as a reference, are experimentally investigated and presented in this study. The main test parameters of this investigation include embedment length, surface type of reinforcing bars, and bar diameter. In particular, the bond mechanism of plain steel reinforcing bars against the surrounding concrete was analyzed by comparing with six-group pullout specimens with aluminium alloy bars. The results indicated that the bond stress experienced by plain bars is quite lower than that of the deformed bars given equal structural characteristics and details. Averagely, plain bars appeared to develop only $18.3 \%$ of the bond stress of deformed bars. Differing from the bond strength of plain steel bars, which is based primarily on chemical adhesion and friction force, the bond stress of aluminium alloy bars is mainly experienced by chemical adhesion and about $0.21 \sim 0.56 \mathrm{MPa}$, which is just one-tenth of that of plain steel bars. Based on the test results, a bond-slip model at the interface between concrete and plain bars is put forward.
\end{abstract}

\section{Introduction}

A large number of existing reinforced concrete buildings were constructed with plain reinforcing bars before the 1970s [1]. Over the past four decades, more and more of these historical structures will undergo structural transformations in order to meet the demands of modern society. In particular, upgrading of a historical structure may be necessary because of deterioration due to corrosion, a change in the structural system, or to rectify initial design and construction faults. The first step in upgrading strategies for addressing existing historical structures is to access the seismic performances of materials and structural systems. It is well known that the overall behavior of reinforced concrete structures is highly dependent on the interaction between steel and concrete. In other words, the behavior of smooth reinforcing bars embedded in concrete is a key issue in the development of reliable procedures for the evaluation of available bearing and/or displacement capacities of historical buildings. Therefore, the bond properties of plain rebar in concrete need to be understood.
Plain reinforcing bar does not exhibit lugs or other surface deformations and therefore cannot transfer bond forces by mechanical interlock. Instead, bond is transferred by adhesion between the concrete and the reinforcing bar before slip occurs, and by wedging action of small particles that break free from the concrete upon slip [2]. Usually, bond behavior is described in terms of a bond stress versus slip relationship. Though the procedure for deducing a bond-slip relationship based on experimental data is not univocally defined [3], pullout tests and beam tests are the common experimental methods used for assessment of bond performance. It is reported that the pullout tests will overestimate the bond capacity of the deformed bars due to friction from the rigid base plate laterally confined to the concrete cylinder. However, plain bars do not transfer bond by mechanical interlock, so the pullout test captures the true failure mechanism and therefore allows for accurate assessment of bond capacity [4].

Besides deformed reinforcing bars epoxy coated have been intensively studied with regard to bond behavior. However, little attention has been paid to the bond behavior of plain reinforcing bars in concrete [5-8]. Also, 
TABLE 1: Material properties.

\begin{tabular}{lccccccc}
\hline Reinforced bar & \multicolumn{3}{c}{ Plain bars } & \multicolumn{3}{c}{ Deformed bars } & \multicolumn{3}{c}{ Al-alloy } \\
Diameter/mm & 8 & 14 & 16 & 14 & 16 & 8 & 14 \\
\hline Yield strength/MPa & 376.7 & 319.1 & 343.1 & 485.8 & 491.9 & 362.1 & 370.9 \\
Ultimate strength/MPa & 521.9 & 441.8 & 463.2 & 687.2 & 660.5 & 378.9 & 399.3 \\
Modulus of elasticity/GPa & 207 & 207 & 207 & 207 & 207 & 68.3 & 75.9 \\
\hline
\end{tabular}

the influence of several parameters affecting bond performance (concrete strength, embedment length, and bar diameter, among others) is not fully established. Actually, the majority of data can be found in the literature aimed at assessing the performance of deformed rebar and defining safe design provisions. Accordingly, smooth rebars are used as a reference but are not fully investigated. Lack of experiments made on this type of specimens translates into a scarce number of reliable models for describing bond performance. Mo and Chan [9] made pullout test with plain rebar and deformed bar and obtained that the bond strength of plain rebar was only $28.6 \%$ that of deformed rebars; Prince and Singh [10] researched the effect of concrete grade on the bond between $12 \mathrm{~mm}$ diameter deformed steel bars and recycled aggregate concrete with the help of 45 pullout tests.

In order to further study the bond behavior between the plain steel bar and surrounding concrete, six-group pullout specimens with plain steel bars and two-group specimens with deformed steel bars conducted for comparison purposes are experimentally investigated. This paper introduces research aiming at characterizing the effects of rebar type, embedment length, the surface type of reinforcing bars, and bar diameter on the bond strength of plain reinforcing bars. Furthermore, considering it is difficult to distinguish adhesive stress from friction stress for the bond strength of plain reinforcing bars, six-group pullout specimens with plain aluminium alloy bars were also constructed to analyze the bond mechanism between plain bars and surrounding concrete in this test [9]. The bond performance between plain aluminium alloy bars and concrete is initially explored by the way. Empirical equations for maximum average bond stress are derived using regression analysis, and the form of the load-slip curve is presented.

\section{Test Programme}

2.1. Material Properties. Fourteen groups of pullout specimens with a bar embedded axisymmetrically were tested. Plain rebars and plain aluminium alloy bars were used in six groups, respectively, and deformed rebar was used in two groups, and each group contained three specimens. The aluminium alloy with the type of 6061-T6 is selected as the plain reinforcing bars in the test. The diameters of the reinforcing bars in this pullout test were $18 \mathrm{~mm}, 14 \mathrm{~mm}$, and $16 \mathrm{~mm}$, respectively. Material properties of these reinforcing bars are given in Table 1.

The concrete had an excepted strength grade of C30 of which the compressive strength is $14.3 \mathrm{MPa}$. Hand mixed concrete was used to cast the specimens. General P42.5 Portland cement was used without admixtures, and the mixing ratio of cement, sand, aggregate, and water was $1: 1.662: 3.091: 0.481$. The results for the 28-day average compressive strength are shown in Table 2. It should be mentioned that the concrete strength was somewhat higher than expected. The mechanical properties of rebar and aluminium alloy bar used in all specimens are shown in Table 2.

2.2. Specimen Preparation and Testing. A total of six-group pullout specimens with plain steel bars and two-group specimens with deformed steel bars, serving as a reference, were cast in this study, and other six-group pullout specimens with aluminium alloy bars were also constructed. Parameters, which are shown in Table 2, include bar size, length of embedment, and surface type of reinforcing bars.

To shorten the disadvantage of stress concentration of concrete at the loading end to bond behavior of the specimen, a plastic pipe was used to avoid interaction between the rebar and the surrounding concrete except in the embedded zone. Sketch map of specimen in the pullout test is shown in Figure 1(a), and picture of real products is shown in Figure 1(b).

2.3. Test Set-Up. The pullout tests were conducted following a procedure similar to ASTM C234 (ASTM 1988); the testing machine is shown in Figure 2. Since slipping of the plain bars at the maximum loading is small, two linear variable different transducers (LVDT) were installed, respectively, on the free end and the loading end to measure the rebar's displacements; test must be ceased while the displacement of the free end exceeded $2 \mathrm{~mm}$ [10]. In addition, in view of the fact that the strain gauge may affect the bond behavior of plain bars, no strain gauge was used in this test.

The value of average nominal bond stress can be calculated as the normal force $F$ divided by the surface area of the rebar embedded in the concrete. For circular cross section reinforcing bar of which the diameter is $d$, the average bond strength can be calculated by the following formula:

$$
\tau_{\mathrm{av}}=\frac{F}{(\pi \cdot d \cdot L)}
$$

where $L$ is the length of embedment. The maximum average bond stress of each specimen can be calculated from (1) while the maximum tensile load occurs.

\section{Experimental Results}

3.1. Failure Mode. For the specimen of plain bars, as the load was applied continuously, slip of the loading end was 
TABle 2: Parameters of test specimens.

\begin{tabular}{|c|c|c|c|c|c|}
\hline Number & Type of rebar & Concrete strength/MPa & Size of specimens/mm & Diameters $/ \mathrm{mm}$ & Embedment length/mm \\
\hline PS14-1 & Plain rebar & 48.5 & 200 & 14 & $100(7 \mathrm{~d})$ \\
\hline PS14-2 & Plain rebar & 48.5 & 200 & 14 & $140(10 \mathrm{~d})$ \\
\hline AA14-1 & Al-alloy & 40.8 & 200 & 14 & $100(7 \mathrm{~d})$ \\
\hline AA14-2 & Al-alloy & 40.8 & 200 & 14 & $140(10 \mathrm{~d})$ \\
\hline S14-1 & Deformed rebar & 48.5 & 200 & 14 & $100(7 \mathrm{~d})$ \\
\hline PS16-1 & Plain rebar & 40.8 & 200 & 16 & $115(7 \mathrm{~d})$ \\
\hline PS16-2 & Plain rebar & 48.5 & 200 & 16 & $160(10 \mathrm{~d})$ \\
\hline AA16-1 & Al-alloy & 40.8 & 200 & 16 & $115(7 \mathrm{~d})$ \\
\hline AA16-2 & Al-alloy & 40.8 & 200 & 16 & $160(10 \mathrm{~d})$ \\
\hline S16-1 & Deformed rebar & 48.5 & 200 & 16 & $115(7 \mathrm{~d})$ \\
\hline PS8-1 & Plain rebar & 40.8 & 150 & 8 & $80(10 \mathrm{~d})$ \\
\hline PS8-2 & Plain rebar & 40.8 & 150 & 8 & $120(15 d)$ \\
\hline AA8-1 & Al-alloy & 40.8 & 150 & 8 & $80(10 \mathrm{~d})$ \\
\hline AA8-2 & Al-alloy & 40.8 & 150 & 8 & $120(15 \mathrm{~d})$ \\
\hline
\end{tabular}
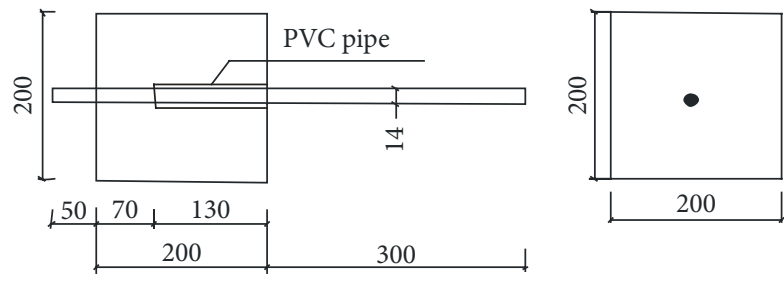

(a)

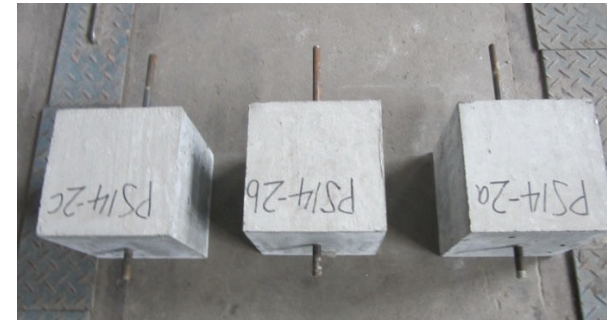

(b)

FIGURE 1: Pullout specimen: (a) schematic diagram and (b) picture of real products.

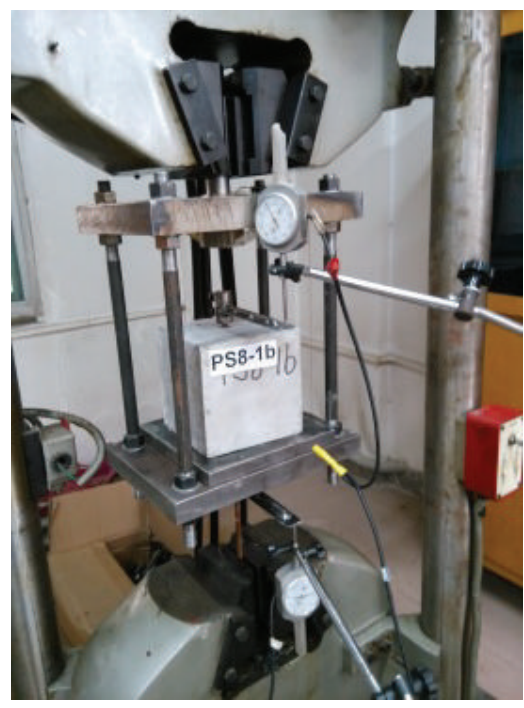

Figure 2: Test set-up.

increasing while no slip occurred at the free end. Slipping at the free end of the bar began while the load approached the maximum and was increasing quickly; then the plain bar was pulled out, and slipping of the loading end increased rapidly at the same time, so the specimen was damaged for the tensile reinforcement was pulled out as shown in Figure 3.

For pullout specimen of deformed bar, while the load reached the maximum, slipping of both the loading end and the free end increased quickly until the slip of the free end exceeded the limited value and then end loading. No slip occurred on the concrete when specimens of deformed bars were damaged; the reason that the specimens were damaged was that the tensile reinforcement was pulled out, as shown in Figure 4. Different from the plain bar, when specimens of deformed bars were damaged, the concrete surrounding the reinforcing bars was pulled out followed by the bars, which indicated that the mechanical interlock played a role.

3.2. Load-Slip Curves. Load versus slip curves of loading end are shown in Figure 5. It indicates that these load-slip curves of plain bars in the pullout test are quite similar, slip was increasing before the maximum load occurrence, and the maximum tensile load occurs at a slight slip and then drops asymptotically to a residual value as the slip increases. For the pullout specimens with the same diameter, the maximum load tends to increase with the length of embedment increasing, the slope of curve of specimen with a large diameter is greater, it indicates that the bond strength of plain bars is effected by diameter, and the variation trend will be analyzed below. Figure 5 indicates that the maximum 


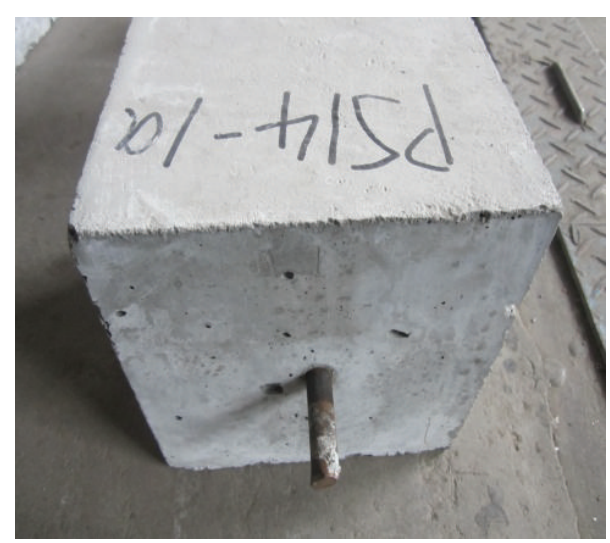

(a)

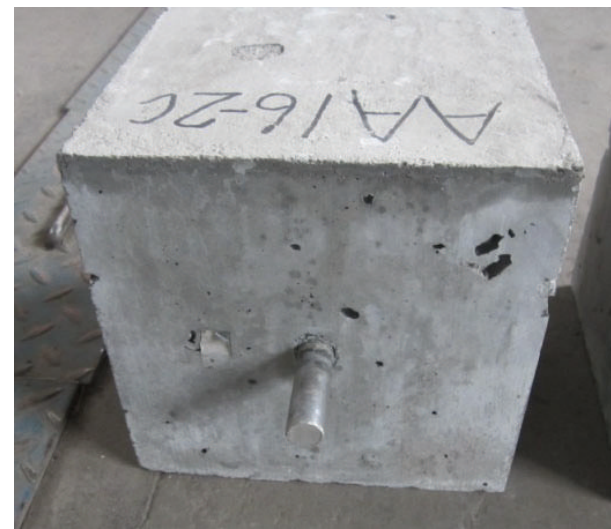

(b)

Figure 3: Pullout failure of plain bars specimens: (a) steel bar and (b) Al-alloy.

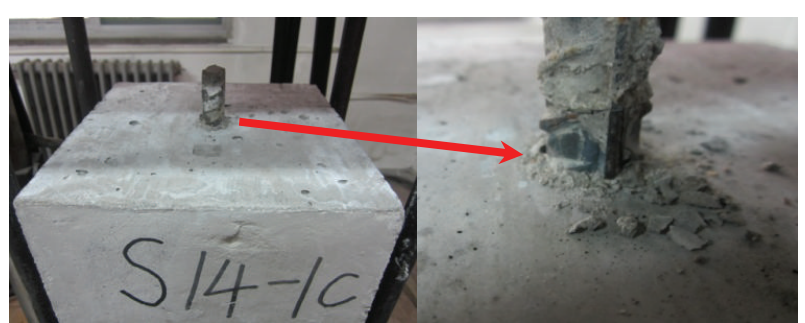

Figure 4: Failure mode of deformed bar specimen.

load of Al-alloy bars in the pullout test is significantly smaller than that of plain bars with the same diameter, and the slip is small when the maximum load occurs. It indicates that the bond-slip mechanisms of them are different.

3.3. Bond Strength. The results of bond behavior between plain bar and surrounding concrete are shown in Table 3. Table 3 indicates that the bond stress of plain bars is significantly smaller than that of deformed bars, and the bond strength of plain Al-alloy is the smallest. While other varieties are in the same value such as the bar diameter and the length of embedment, the bond strength of plain bars is $18.3 \%$ of that of deformed bars.

3.3.1. Superficial Form of Bars. Changes in relationship between the bond strength of the specimens and the superficial form of bars are shown in Figure 6. It indicates that, among the specimens with the length of embedment of $7 \mathrm{~d}$, the maximum bond strength of them is deformed ribbed bars, the value is about $20 \mathrm{MPa}$, and the minimum is the bond strength of Al-alloy which is less than 0.5 MPa. The reason is that the bond strength of plain Al-alloy merely consists of adhesive stress, which is about 0.2 to $0.5 \mathrm{MPa}$, while the plain bar has a rough surface, the plain bars are not plain thoroughly due to residual small particles after manual derusting, and both adhesive stress and force of friction play a role. The bond strength of deformed bars mainly depends on the mechanical interlock; obviously the mechanical interlock of ribbed bars is far greater than adhesive stress and force of friction. The bond strength of a specimen with the length of embedment of $10 \mathrm{~d}$ is still greater than that of Al-alloy.

3.3.2. Length of Embedment. The variations of bond strength of different specimens are shown in Figure 7. It indicates that increasing the length of embedment makes no significant influence on bond strength of specimen with plain Al-alloy. The reason may be that the bond strength of plain Al-alloy has a barrier oxide film that is bonded strongly to its surface [11]; it is so smooth that the force of friction can be neglected. However, for a plain bar with diameter of $8 \mathrm{~mm}$, when the length of embedment increases to $120 \mathrm{~mm}$, the bond strength is obviously larger than that of $80 \mathrm{~mm}$, which is about nine times larger; this changes possibly due to the difference of bond mechanism, in which the bond strength of the latter is just composed of adhesive stress, and the former is composed of adhesive stress and force of friction. In view of the fact that it is difficult to distinguish adhesive stress and force of friction from the bond strength, more systematic research data should be offered to research further.

3.3.3. Bar Diameter and Concrete Strength. Previous research [6] indicated that bond strength of plain rebar decreases with increasing bar diameter. It can be obtained from Table 3 that the average bond stress of specimens with identical development length is somewhat greater for $14 \mathrm{~mm}$ diameter bars than for $16 \mathrm{~mm}$ diameter bars while the plain bar diameter must meet the requirements in the code "standard method for testing of concrete structures" [12], which is much greater than $10 \mathrm{~mm}$, or it will cause a larger discreteness, such as bond strength of the plain bar which is $8 \mathrm{~mm}$ in diameter. The longer the length of embedment, the smaller the amplitude reduction of the bond strength; the reason is that with the length of embedment increasing the bond stress distributions tend to be uniform, and reduction of the bond strength results from diameter increasing tending to be more uniform while the bond strength of the plain Al-ally is so small that no obvious change rule occurs with the diameter increasing. 


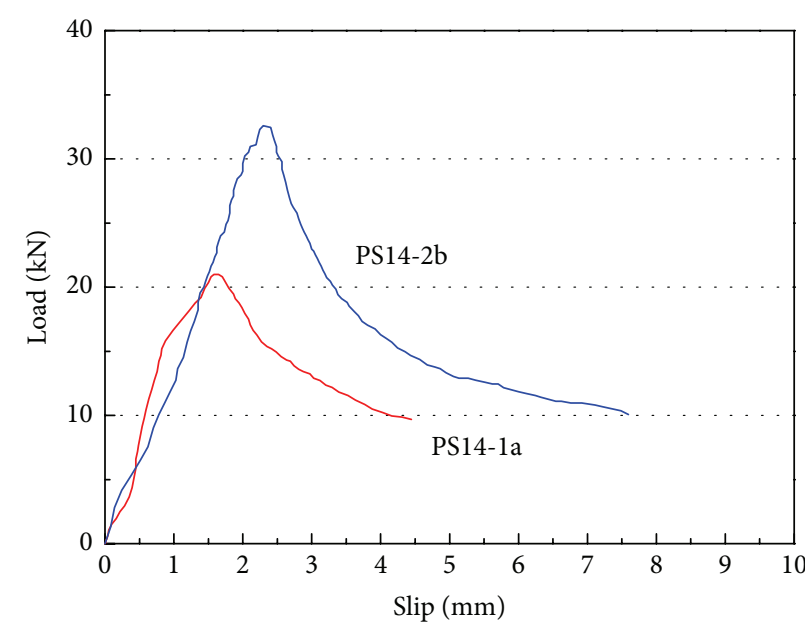

(a)

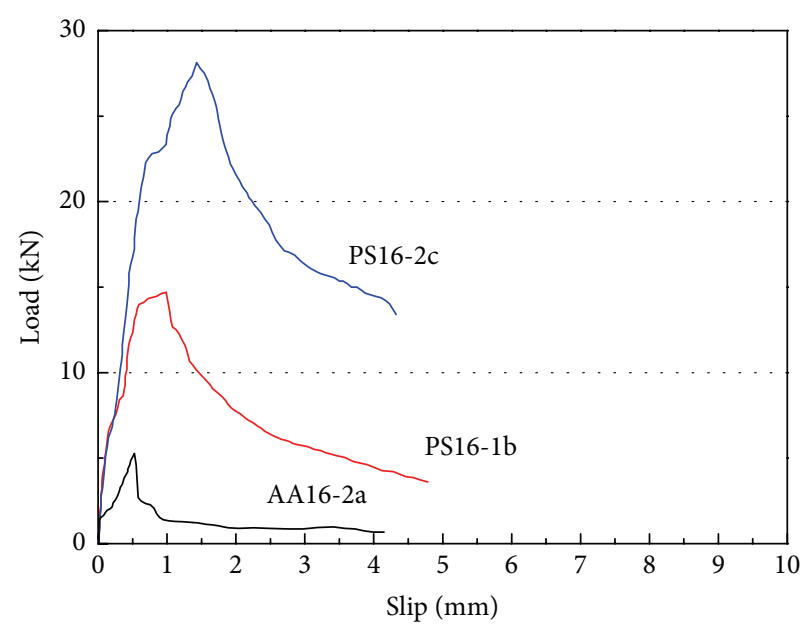

(b)

FIGURE 5: Load versus slip curves of typical specimens: (a) diameter of $14 \mathrm{~mm}$ and (b) diameter of $16 \mathrm{~mm}$.

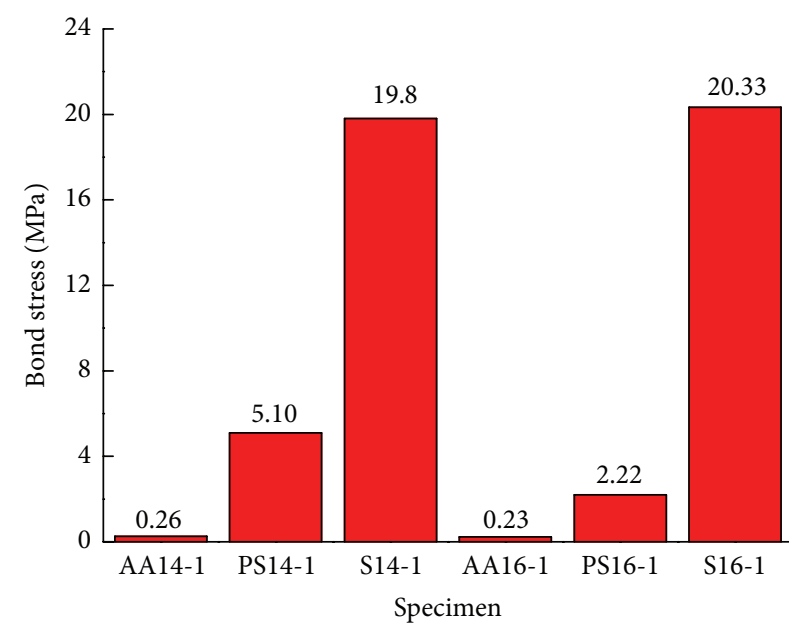

(a)

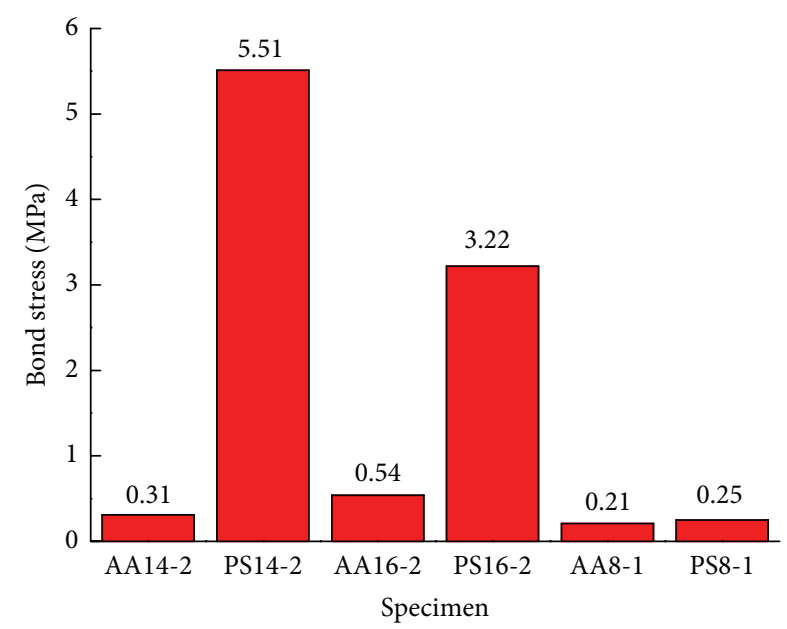

(b)

FIGURE 6: Effect of type of bar surface on bond strength: (a) length of embedment of $7 \mathrm{~d}$ and (b) length of embedment of $10 \mathrm{~d}$.

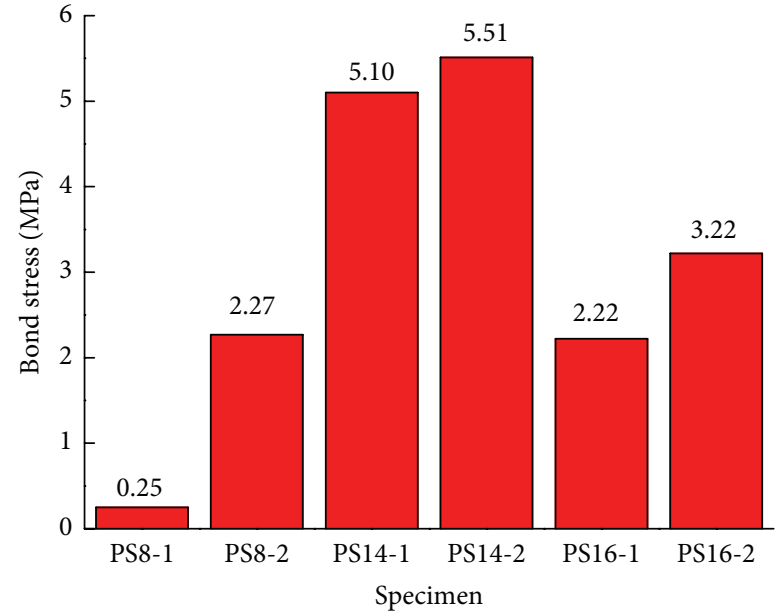

(a)

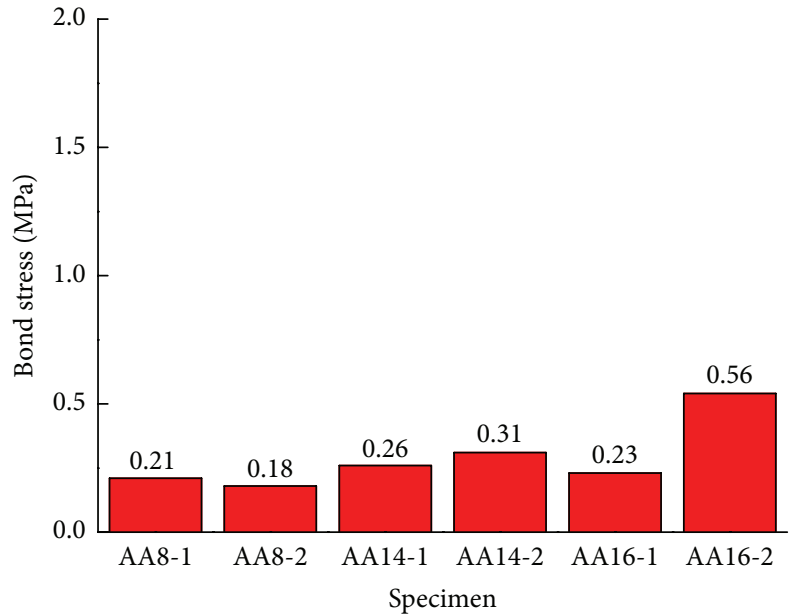

(b)

FIGURE 7: Effect of embedment length on bond strength of plain bars: (a) plain bar and (b) plain Al-alloy. 
TABLE 3: Main test results.

\begin{tabular}{|c|c|c|c|c|c|c|}
\hline Number & $\begin{array}{c}\text { Concrete } \\
\text { strength/MPa }\end{array}$ & Diameters/mm & $\begin{array}{c}\text { Length of } \\
\text { embedment/mm }\end{array}$ & $\begin{array}{c}\text { Maximum load } \\
P_{\max } / k \mathrm{~N} \\
\end{array}$ & $\begin{array}{c}\text { Bond strength } \\
\tau_{\max } / \mathrm{MPa}\end{array}$ & $\begin{array}{c}\text { Average value } \\
\tau_{\mathrm{av}} / \mathrm{MPa}\end{array}$ \\
\hline PS14-1a & & & & 21.05 & 4.79 & \\
\hline PS14-1b & 48.5 & 14 & 100 & 24.27 & 5.52 & 5.10 \\
\hline PS14-1c & & & & 22.00 & 5.00 & \\
\hline PS14-2a & & & & 34.88 & 5.66 & \\
\hline PS14-2b & 48.5 & 14 & 140 & 32.68 & 5.31 & 5.51 \\
\hline PS14-2c & & & & 34.14 & 5.54 & \\
\hline AA14-1a & & & & 1.03 & 0.23 & \\
\hline AA14-1b & 40.8 & & 100 & 0.98 & 0.22 & 0.26 \\
\hline AA14-1c & & & & 1.46 & 0.33 & \\
\hline AA14-2a & & & & 2.06 & 0.33 & \\
\hline AA14-2b & 40.8 & 14 & 140 & 5.84 & 0.95 & 0.31 \\
\hline AA14-2c & & & & 1.76 & 0.29 & \\
\hline S14-1a & & & & 91.69 & 20.85 & \\
\hline $\mathrm{S} 14-1 \mathrm{~b}$ & 48.5 & 14 & 100 & 79.64 & 18.11 & 19.80 \\
\hline S14-1c & & & & 89.90 & 20.44 & \\
\hline PS16-1a & & & & 11.05 & 1.91 & \\
\hline PS16-1b & 40.8 & 16 & 115 & 14.97 & 2.59 & 2.22 \\
\hline PS16-1c & & & & 12.42 & 2.15 & \\
\hline PS16-2a & & & & 30.13 & 3.75 & \\
\hline PS16-2b & 48.5 & 16 & 160 & 19.25 & 2.39 & 3.22 \\
\hline PS16-2c & & & & 28.32 & 3.52 & \\
\hline AA16-1a & & & & 1.40 & 0.24 & \\
\hline AA16-1b & 40.8 & 16 & 115 & 1.46 & 0.25 & 0.23 \\
\hline AA16-1c & & & & 1.14 & 0.20 & \\
\hline AA16-2a & & & & 5.38 & 0.67 & \\
\hline AA16-2b & 40.8 & 16 & 160 & 4.29 & 0.53 & 0.54 \\
\hline AA16-2c & & & & 3.31 & 0.41 & \\
\hline S16-1a & & & & 111.02 & 19.21 & \\
\hline $\mathrm{S} 16-1 \mathrm{~b}$ & 48.5 & 16 & 115 & 120.78 & 20.89 & 20.33 \\
\hline S16-1c & & & & 120.70 & 20.88 & \\
\hline PS8-1a & & & & 0.60 & 0.30 & \\
\hline PS8-1b & 40.8 & 8 & 80 & 0.56 & 0.28 & 0.25 \\
\hline PS8-1c & & & & 0.35 & 0.17 & \\
\hline PS8-2a & & & & 4.44 & 1.47 & \\
\hline PS8-2b & 40.8 & 8 & 120 & 7.31 & 2.42 & 2.27 \\
\hline PS8-2c & & & & 8.76 & 2.90 & \\
\hline AA8-1a & & & & - & - & \\
\hline AA8-1b & 40.8 & 8 & 80 & 0.37 & 0.18 & 0.21 \\
\hline AA8-1c & & & & 0.46 & 0.23 & \\
\hline AA8-2a & & & & 0.42 & 0.14 & \\
\hline AA8-2b & 40.8 & 8 & 120 & 0.57 & 0.19 & 0.18 \\
\hline AA $8-2 c$ & & & & 0.64 & 0.21 & \\
\hline
\end{tabular}

Note: in the above table, the data of AA8-1a was not got for reason of operation; and data of AA14-2b is anomalous and was wiped off then. 

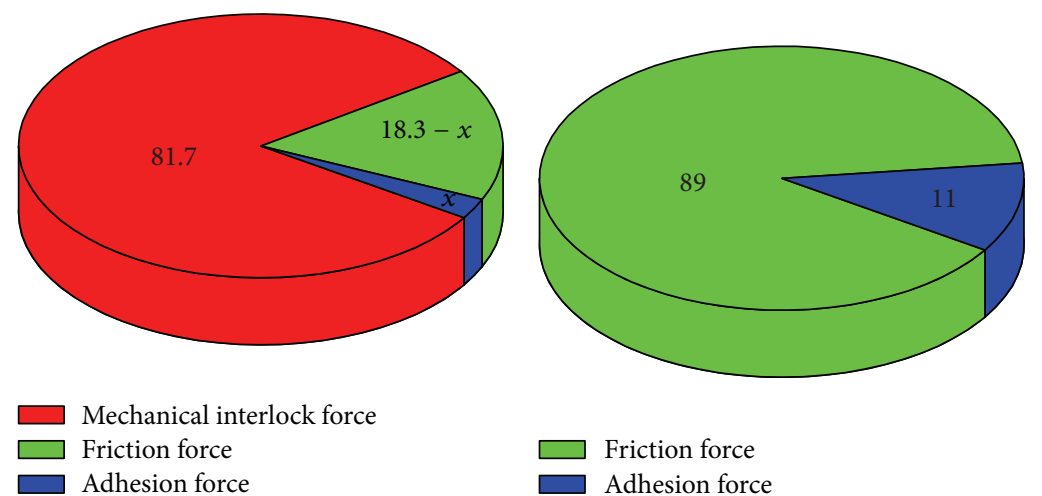

Adhesion force

(b)

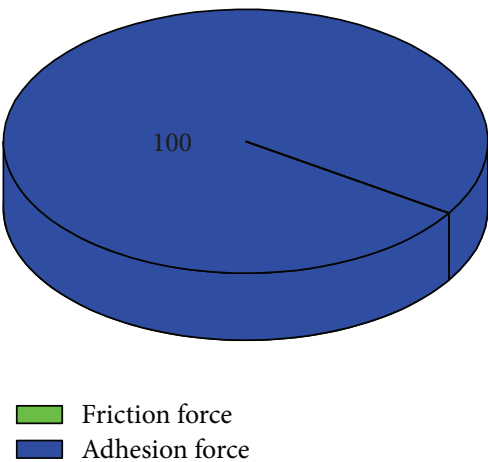

(c)

FIGURE 8: Constitution of bond strength: (a) deformed bar, (b) plain bar, and (c) plain Al-alloy.

The change of concrete strength may influence the bond strength of deformed bars because hardness of concrete is related to the mechanical interlock of deformed bars. However, the bond strength of plain bars is mainly composed of adhesive stress and friction and shows no dependence on mechanical interlock. Therefore, the variety of concrete strength has no obvious influence on bond strength of plain bars. Although the concrete strengths of PS16-1 and PS16-2 in Table 3 are different, the variety of bond strength mainly depends on the increase of the bond length.

\section{Bond Mechanism}

As is known, the bond strength of deformed bars consists of three parts: (1) adhesion between the concrete and the reinforcing bar; (2) fraction between the reinforcing bar and the surrounding concrete; and (3) mechanical interlock for the roughness of bar surface, and the bond strength mainly depends on mechanical interlock. Literature [13] has received the same conclusion on the research of bond performance of GFRP deformed bars.

According to the result of this test, the compositions of ribbed bars is shown in Figure 8(a). Combined with the data of plain bars, adhesive stress in Figure 8(a) is about 2\% to 5\% of the bond strength.

Different from ribbed bars, the bond strength of plain bar is composed of adhesive stress and friction, which mostly depends on friction. According to the testing result, suppose that specimen PS8-1 only has adhesive stress and then the composition of bond strength of plain bars is composed as Figure $8(\mathrm{~b})$, which is 0.21 to $0.56 \mathrm{MPa}$, and about $1 / 10$ that of plain bars, which is shown in Figure 8(c).

\section{Bond Stress-Slip Model}

Knowledge of bond-slip relationship will be useful when assessing the bond capacity of members adjacent to cracks, where local strain compatibility between the bar and the surrounding concrete is lost. According to the previous research [14], the bond-slip curve of reinforcing bars and surrounding concrete is analyzed by the following equation:

$$
\begin{aligned}
\text { ascent: } & \frac{\tau_{\mathrm{av}}}{\tau_{u}}=\left(\frac{s}{s_{u}}\right)^{a}, \\
\text { downgrade: } & \frac{\tau_{\mathrm{av}}}{\tau_{u}}=\frac{s / s_{u}}{b\left(s / s_{u}-1\right)^{3}+s / s_{u}},
\end{aligned}
$$

where $\tau_{\mathrm{av}}$ is the average bond stress of reinforcing bar and $s$ is the slipping of reinforcing bar; $\tau_{u}$ is bond strength at the maximum load and $s_{u}$ is the slipping at the maximum load; $a$ and $b$ are parameters of ascent and downgrade of the bond stress-slip curve, respectively, which can obtain via plenty of test data. As the data of this test is limited, referencing the research results of literature [14], then suggest that $a$ is equal to 0.3 and $b$ is equal to 0.5 .

According to (2a) and (2b), average bond stress-slip of specimen of plain bars is calculated theoretically; the curve of test and calculation are contrasted in Figure 9. It can be concluded that the predicted curves agree well with the test curves of specimens.

\section{Conclusions}

(1) For pullout specimens, the free end has no slip at the early loading when part of plain bar bonded. Slipping at the free end began and then increased rapidly with added loading increase to the maximum, then the plain bar is pulled out quickly, and test specimen damaged for the reinforcing bar was pulled out.

(2) While other varieties, such as the bar diameter and the length of embedment, are in the same value, the bond strength of plain bars is significantly smaller than deformed bars, which is about $18.3 \%$ that of deformed bars.

(3) At constant length of embedment, with the increasing of reinforcing bar diameter, the bond strength of plain bars decreased, while plain $\mathrm{Al}$-alloy has no significant changes. 


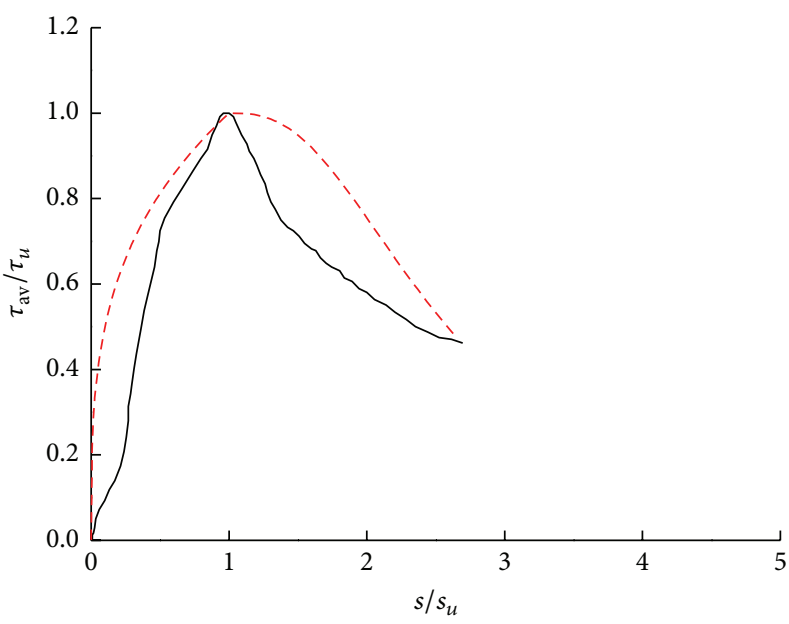

- Test

- - - Prediction

(a)

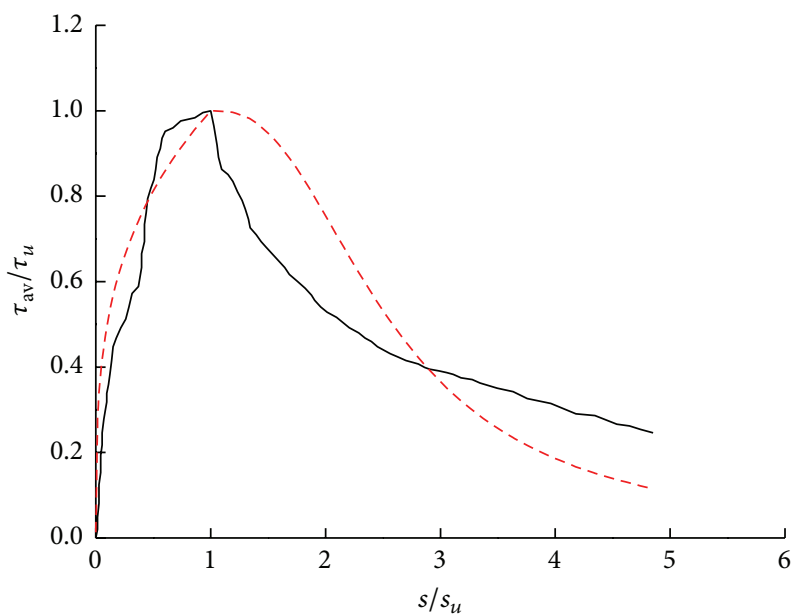

- Test

-.. Prediction

(c)

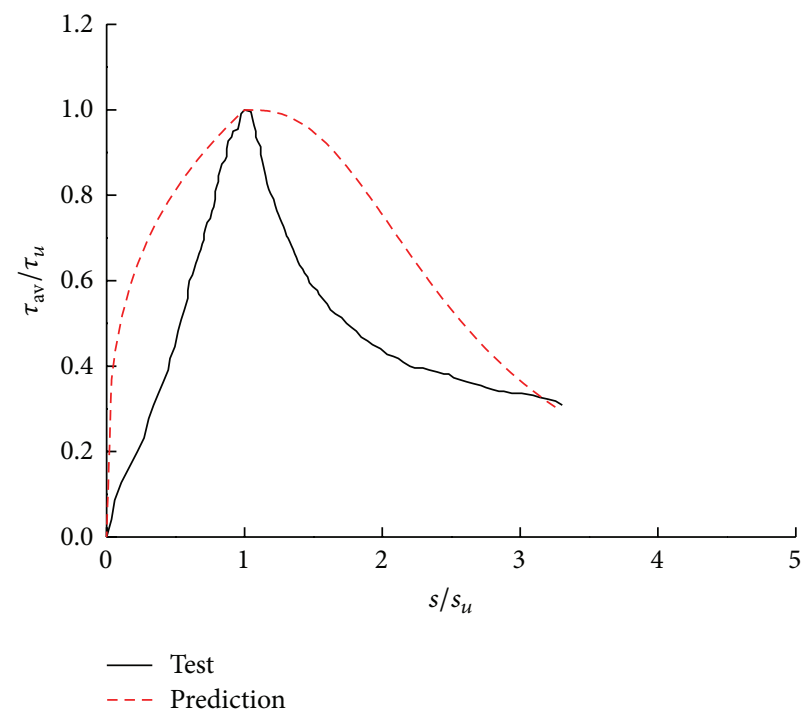

(b)

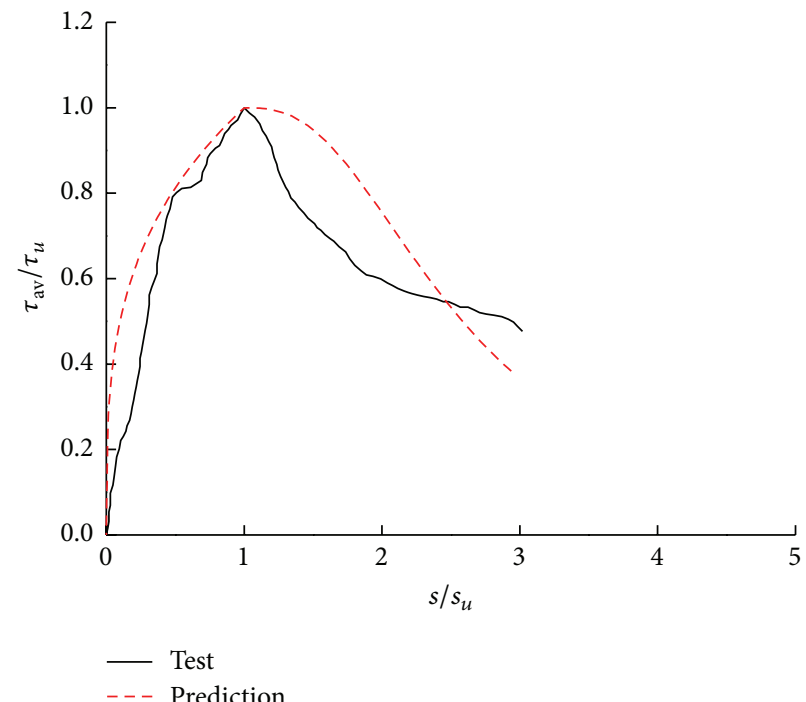

(d)

FIGURE 9: Comparisons of bond-slip curve between test results and predicted results: (a) specimen of PS14-1, (b) specimen of PS14-2, (c) specimen of PS16-1, and (d) specimen of PS16-2.

(4) The bond strength of plain bar is composed of adhesive stress and friction and mainly depends on the friction. Nevertheless, the bond strength of Alalloy is just composed of adhesive stress, which is about 0.21 to $0.56 \mathrm{MPa}$ as $1 / 10$ that of plain round bar.

(5) The bond-slip curve of the loading end of plain bars and concrete interface can be calculated theoretically from (2a) and (2b). However, more systematic research data should be offered to further improve this bond-slip model.

\section{Conflict of Interests}

The authors declare that there is no conflict of interests regarding the publication of this paper.

\section{Acknowledgments}

The authors gratefully acknowledge the support provided by the Research Fund for Natural Science Foundation of China (no. 51108032) and by Foundation of Changan University (no. 310828152017 and no. 2013G3282015).

\section{References}

[1] E. Hertanto, Seismic assessment of pre-1970s reinforced concrete structures [Ph.D. thesis], University of Canterbury, Christchurch, New Zealand, 2005.

[2] D. A. Abrams, Tests of Bond Between Concrete and Steel, University of Illinois Bulletin no. 71, University of Illinois at Urbana-Champaign, Urbana, Ill, USA, 1913. 
[3] G. M. Verderame, G. De Carlo, P. Ricci, and G. Fabbrocino, "Cyclic bond behaviour of plain bars. Part II: analytical investigation," Construction and Building Materials, vol. 23, no. 12, pp. 3512-3522, 2009.

[4] L. R. Feldman and F. M. Bartlett, "Bond stresses along plain steel reinforcing bars in pullout specimens," ACI Structural Journal, vol. 104, no. 6, pp. 685-692, 2007.

[5] Y. Xu, Experimental study on bond anchorage behaviors between deformed reinforcing bars and concrete [Ph.D. thesis], Tsinghua University, Beijing, China, 1990, (Chinese).

[6] L. R. Feldman and F. M. Bartlett, "Bond strength variability in pullout specimens with plain reinforcement," ACI Structural Journal, vol. 102, no. 6, pp. 860-867, 2005.

[7] M. N. Hassan and L. R. Feldman, "Behavior of lap-spliced plain steel bars," ACI Structural Journal, vol. 109, no. 2, pp. 235-244, 2012.

[8] G. Fabbrocino, G. M. Verderame, and G. Manfredi, "Experimental behaviour of anchored smooth rebars in old type reinforced concrete buildings," Engineering Structures, vol. 27, no. 10, pp. 1575-1585, 2005.

[9] Y. L. Mo and J. Chan, "Bond and slip of plain rebars in concrete," Journal of Materials in Civil Engineering, vol. 8, no. 4, pp. 208211, 1996.

[10] M. J. R. Prince and B. Singh, "Bond behaviour of normal- and high-strength recycled aggregate concrete," Structural Concrete, vol. 16, no. 1, pp. 56-70, 2015.

[11] J. R. Kissell and R. L. Ferry, Aluminum Structures: A Guide to Their Specifications and Design, John Wiley \& Sons, 2002.

[12] X. Hu, D. Niu, and Y. Zhang, "Experimental research on bond performance of reinforcement and fly ash concrete," Journal of Building Structures, vol. 34, no. 1, pp. 139-146, 2013 (Chinese).

[13] L. Jingan and X. Yongsheng, Application and Development of Aluminium Alloy Materials, Metallurgical Industry Press, Beijing, China, 2011 (Chinese).

[14] GB50152-92, Standard Method for Testing of Concrete Structures, China Architectural \& Building Press, Beijing, China, 1992. 

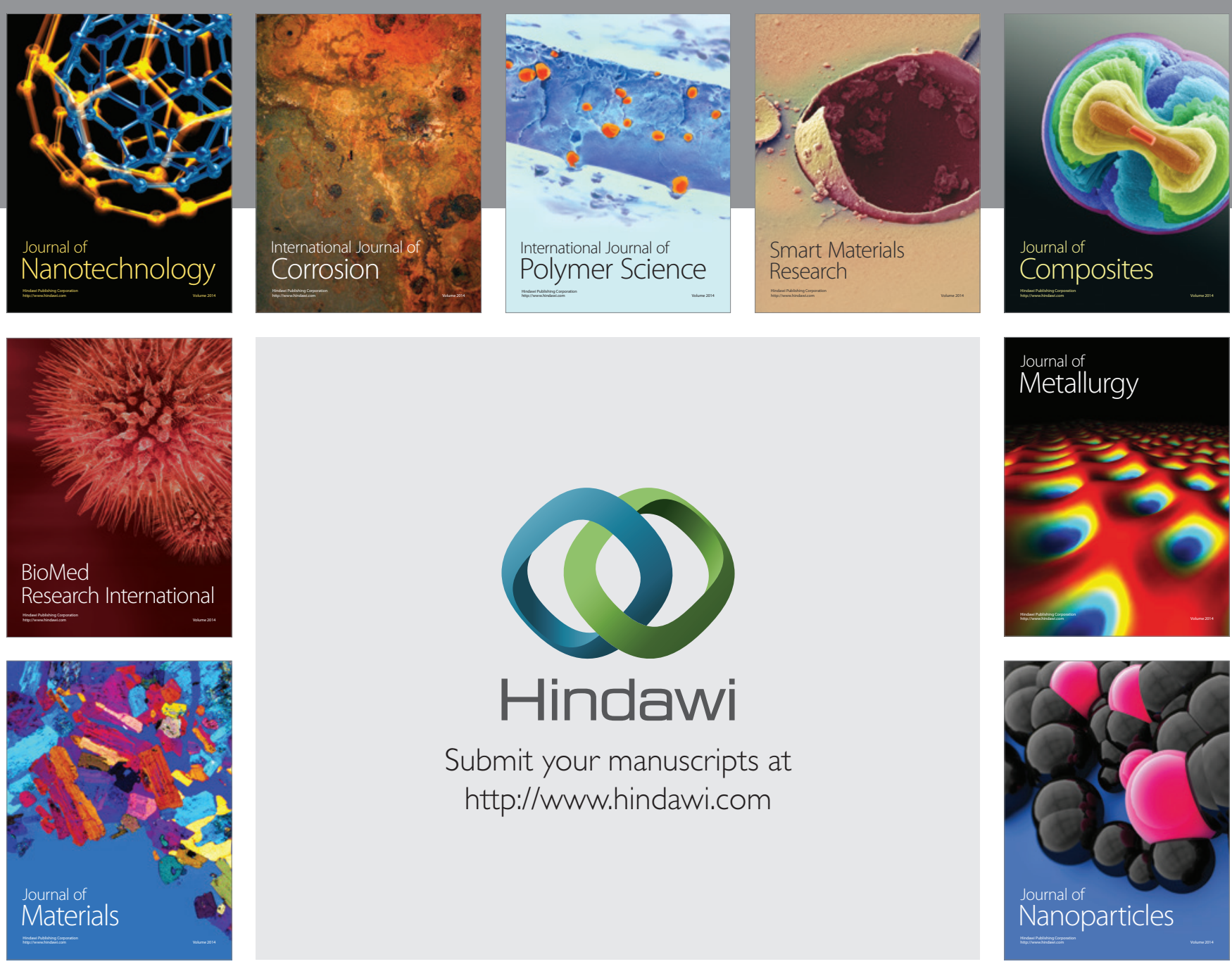

Submit your manuscripts at http://www.hindawi.com
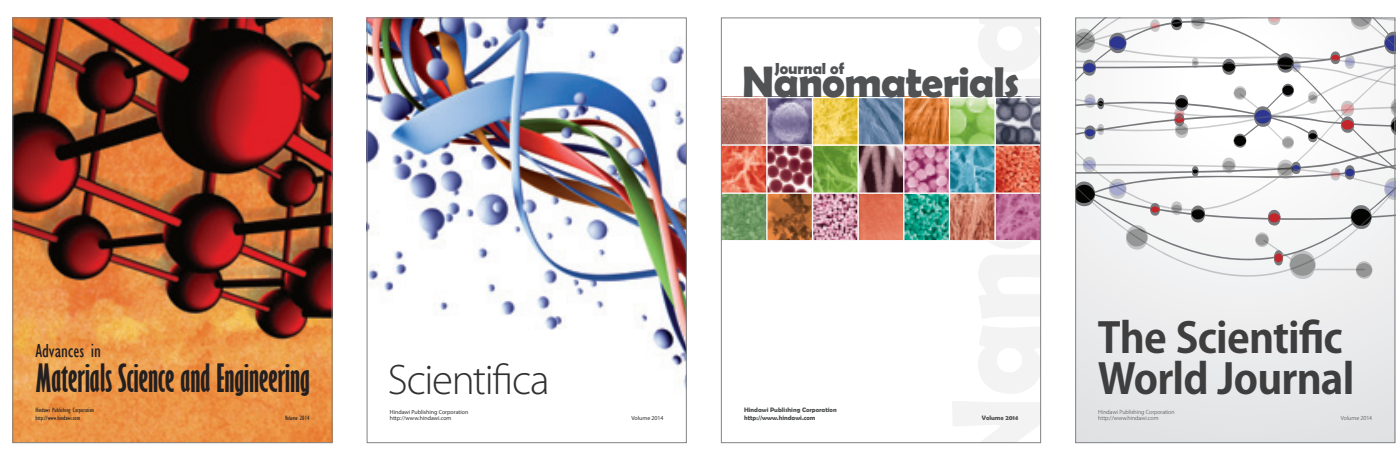

\section{The Scientific World Journal}
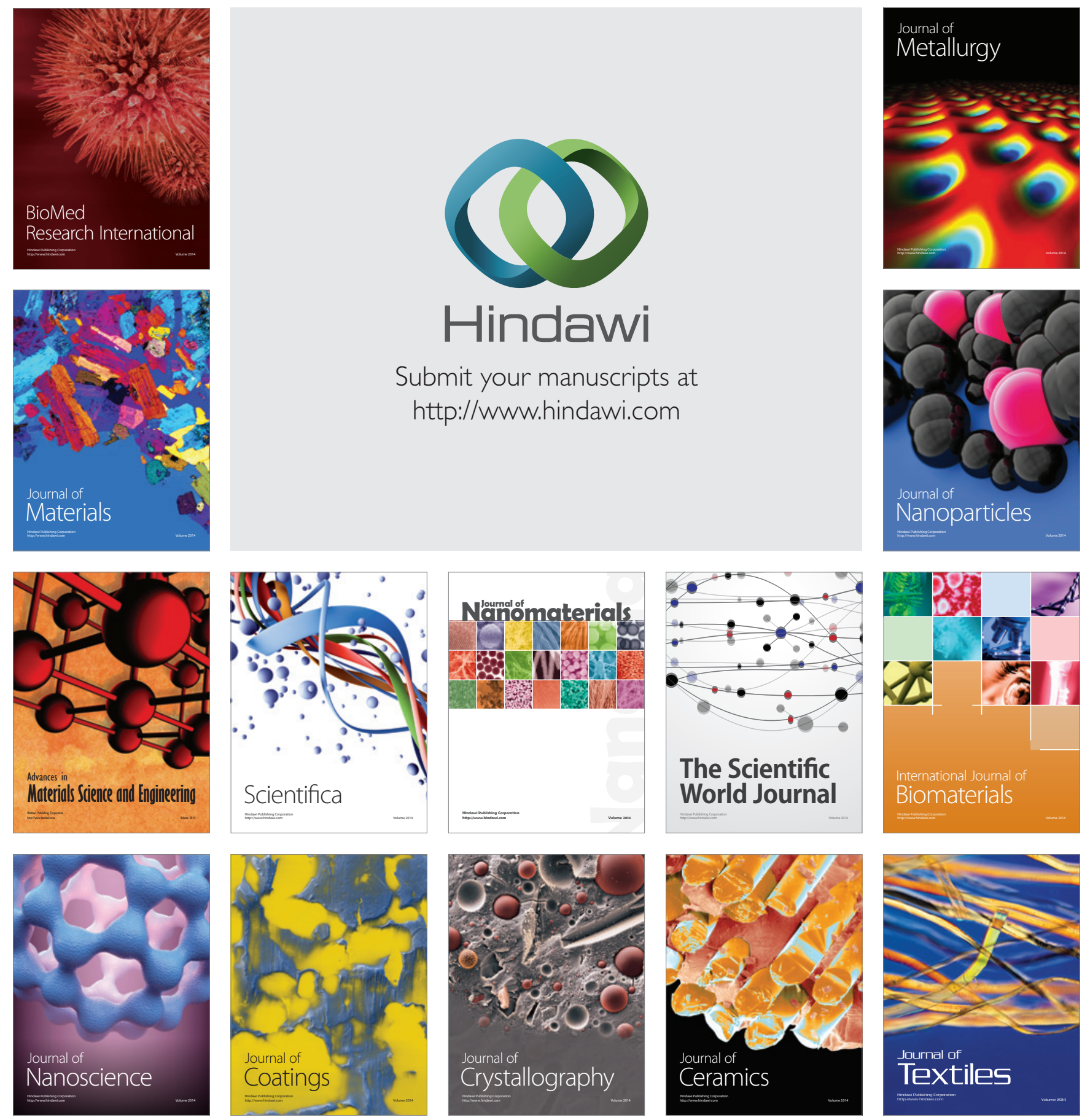